\title{
The Design and Finite Element Analysis of Emergency Escape Ladder for High-Rise Building

\author{
Yu-jing $\mathrm{He}^{\mathrm{a}}$, Ya-dong Tang ${ }^{\mathrm{b}}$ and ${\mathrm{He} \mathrm{Li}^{\mathrm{C}^{*}}}$
}

The Agriculture University of Henan, College of Machinery and Electronic Engineering, Zhengzhou, China, 450002

aheyujinghn@126.com; ${ }^{\circ}$ chungbuk@163.com

${ }^{*}$ Corresponding author

Keywords: Security, Emergency Escape Ladder, Finite Element Analysis, ANSYS.

\begin{abstract}
An emergency escape ladder which is applied in emergency, for rescue and escaping is designed in this paper to meet the urge needs in modern society. As the major bearing part of the whole ladder, the ladder assembly's rigidity and strength determines the safety and reliable running of the ladder. This paper used the finite element analysis software ANSYS for nonlinear mechanics analysis of the first-section ladder, obtained the distribution diagram stress and strain, gave analysis results of the rigidity and strength, and provided an improved method and recommendations.
\end{abstract}

\section{Introduction}

With the industrialization and urban development, the casualties and direct economic loss by fire has presented a corresponding increased trend. In particular, the progressively increased modern urban high-rise building and larger density of building make the fire rescue in higher buildings more and more difficult. There are few relevant domestic researches at present, and the similar domestic instruments are not mature enough, but at the same time, the society has put forward increasingly high requirements on the rescue devices in high-rise buildings. For this reason, this paper designed a kind of emergency escape ladder. As set above the balcony, it is usually in a folded state, but opened under dangerous situation to help trapped men fall to earth quickly. This ladder can be used for self rescue of both trapped men and firefighters. Again, it would not subject to storey height, for which the precious time is saved. The main stress should be assumed by the ladder assembly, so enough rigidity and strength needs to be satisfied. The traditional strength calculation mainly employs the material mechanics method and selects larger security coefficient to guarantee the rigidity of ladder assembly [1]. With the development of CAE technology, employing the finite element analysis can calculate the stress and strain of each unit more accurately. In this way, the stress and strain of each unit can be clearly observed and the unreasonable then can be timely found out and thus provide the basis for rational design of ladder assembly. The details are shown as below.

\section{Integral Analysis and Operating Principle Introduction of the Ladder}

The integral structure of this emergency escape ladder for high-rise building can be seen in Figure1,mainly including three sections of the ladder, rescure pedal, screw, sliding block, etc. After starting the power section of automatic rescue ladder (motor) by remote control device, the motor makes the sliding block slide to the right under the effect of screw through the drive part (bevel gear, screw). In this way, the emergency escape ladder would be initiated, and the second and third ladder would be rapidly deployed under its own weight. Again, a good join with the next storey would be achieved to complete the stretching link of automatic rescue ladder. When you need to pack up the ladder tore duce the occupied space, you can start the motor by remote control device, pull up rope around the rope sheave, and tuck up the ladder from bottom to top, wherein the folding process is rather opposite to the deploying process. Finally, the ladder should be folded neatly beneath the pedal and wholly complete the folding process. 
The external forces suffered by the ladder are: horizontal pressure force by the wall, support force by the ground, static friction force by the ground hindering the movement trend, and the gravity by the man who stands on the ladder [2]. The internal forces suffered by the ladder are: force of friction between the wire rope and the ladder, and the tensile force. This paper then took the first-section ladder as an example and adopted finite element analysis software ANSYS for nonlinear mechanics analysis of the first-section ladder.

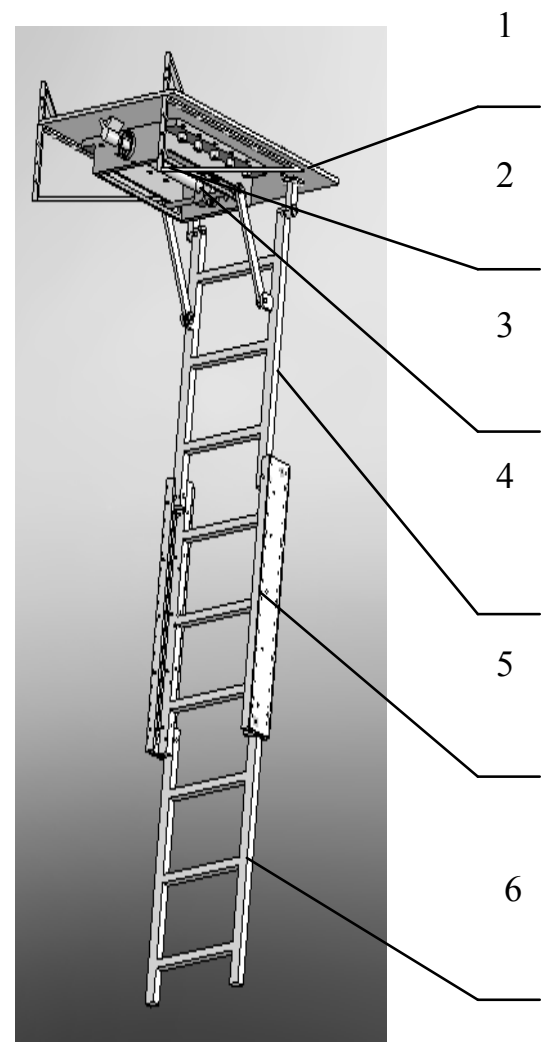

Figure 1, Operating Principle screw Diagramof Self-Rescue Ladder

1. rescure pedal 2. screw 3. sliding block4.first-sectionladder5.second-section ladder 6. third-section ladder

\section{FEA of First-Section Ladder}

\section{Establishment of Geometric Model}

In the finite element analysis, the modeling precision of finite element model plays a great rule in the analysis result, and the modeling workload sometimes accounts for over $80 \%$ of the total. For this ground, the model quality even determines the application value and the guiding practice of analysis result [3]. The first-section ladder employs the modeling method that is from bottom to top and directly finish the modeling of parts for the simplified model in ANSYS [4].

\section{Structural Analysis}

The model of this ladder can be seen in Figure 2. The actual ladder assembly is mainly made up of two rectangular steel tubes, which are connected by three beams. There are two rigidity ears on the steel, which connects to the upper diaphragm of the tripod. The parameters of the rectangular steel tube are shown in Table 1.

Theoretical Weight Calculate Formula of Steel Pipe 
$\mathrm{W}=($ length of side + length of side $) \times 2 \times$ wall thickness $\times 0.00785 \times$ length
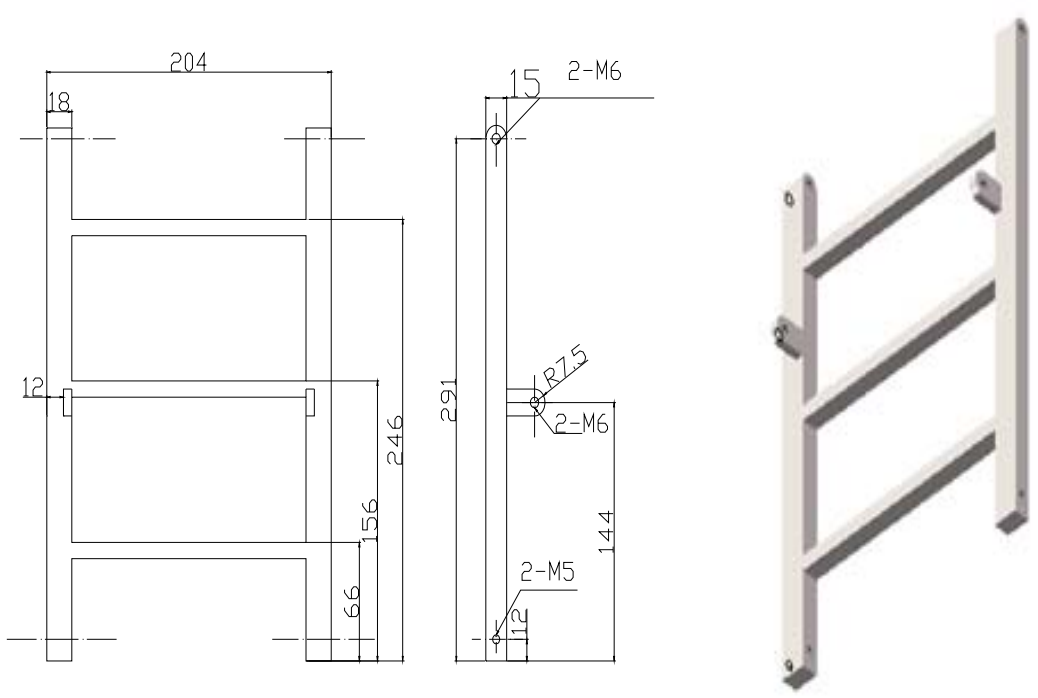

Figure 2, Model and Dimensional Drawing of First-Section Ladder

Table 1, Part Parameters of the Rectangular Steel Tube (GB/T3094-2000)

\begin{tabular}{cccccc}
\hline length of side & wall thickness & area of section & $\begin{array}{c}\text { theoretical } \\
\text { weight }\end{array}$ & $\begin{array}{c}\text { inertia } \\
\text { moment }\end{array}$ & $\begin{array}{c}\text { section } \\
\text { modulus }\end{array}$ \\
\hline$/ \mathrm{mm}$ & $/ \mathrm{mm}$ & $/ \mathrm{cm}^{2}$ & $\mathrm{~kg} / \mathrm{M}$ & $/ \mathrm{cm}^{3}$ & $/ \mathrm{cm}^{4}$ \\
\hline 40 & 5 & 6.98 & 5.48 & 16.56 & 7.87 \\
\hline 60 & 5 & 10.58 & 8.30 & 54.57 & 18.19 \\
\hline
\end{tabular}

\section{Establishment and Analysis of Finite Element Model}

\section{Analysis and Selection of Element Type}

In this section of ladder, profiles (beam column, etc.) materials are mainly involved. Based on the characteristics of loading and units, this paper directly used the defined material properties for finite element modeling of in the finite element calculation.

Solid45 unit is used to construct 3D solid structure, units are defined by the eight nodes, and each node has the three degrees of translation freedom along the direction of the xyz. An unit has plasticity, creep, expansion, stress intensification, large deformation and strain capacity, so Solid45 unit is selected for discrete.

The structure only has the bearing connection form, which is mainly the compression. The simplified model could be regardless of the rectangular steel tube, but to define all by cuboid entity without bolt hole, as shown in Figure 3. 


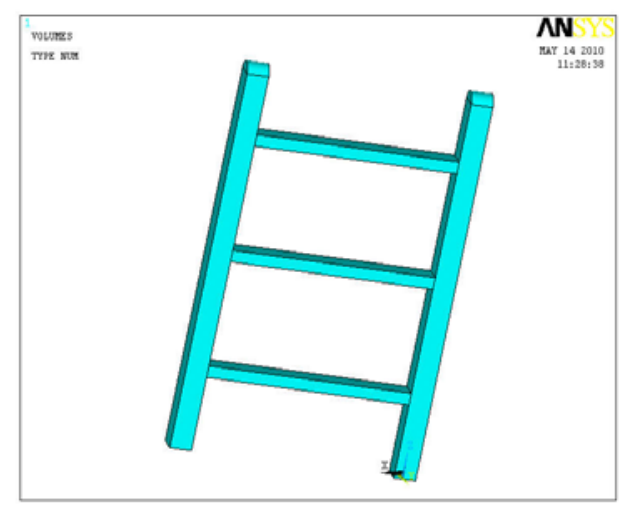

Figure 3, Simplified Model

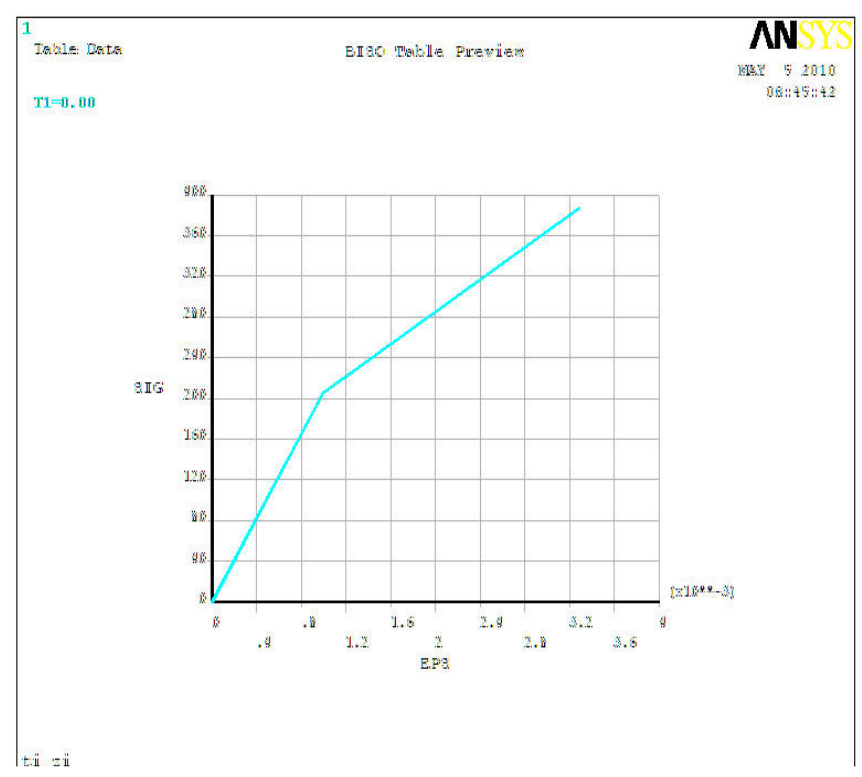

Figure 4, Stress-Strain Relationship of the Defined Materials

\section{Material Properties}

The ladder materials are 0Cr18Ni9 stainless steel (nickel-chrome steel, alloy steel), elasticity modulus $\mathrm{E}=2.06 \times 1011 \mathrm{~Pa}$, the Poisson's ratio $\mu=0.3$, shear modulus $\mathrm{G}=7.938 \times 1010 \mathrm{~Pa}$, strength of extension $\sigma \mathrm{b} \geqq 520 \mathrm{Mpa}$, offset yield strength $\sigma 0.2 \geqq 205 \mathrm{Mpa}$, elongation rate $\sigma 5 \geqq 40 \%$, reduction rate of area $\Psi \geqq 60 \%$. Through the properties of the defined materials, the stress-strain curve of the materials can be obtained, as shown in Figure 4.

\section{Grid Division}

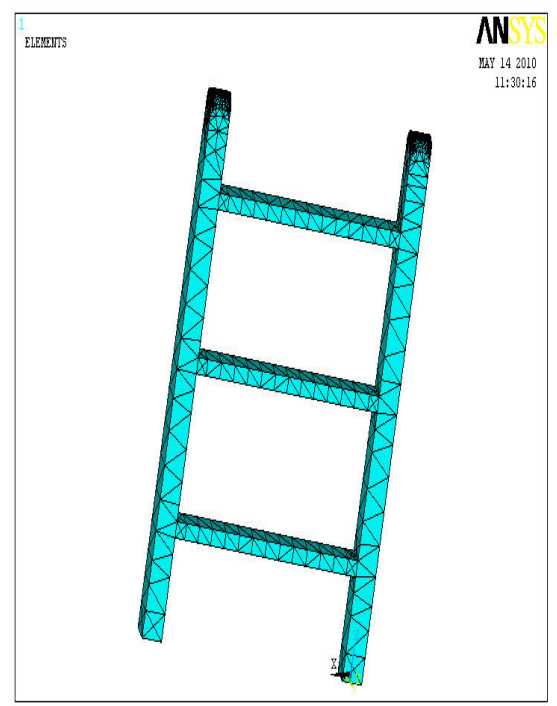

Figure 5, Grid Division of the

First-Section Ladder

The geometric model mainly allows for the surface entity, the beam and vertical rods on the both sides are welded together, wherein the weld is the whole contacting length. The weld is not considered in order to simplify the mesh partition grid. In the process of grid division, this paper used solid45 unit and triangular elements, while for the highest precision, the free grid is selected. Through the above analysis, the finite element model established for the first-section ladder is shown in Figure 5. After the grid division, there are totally 2169 nodes and 7748 units. 


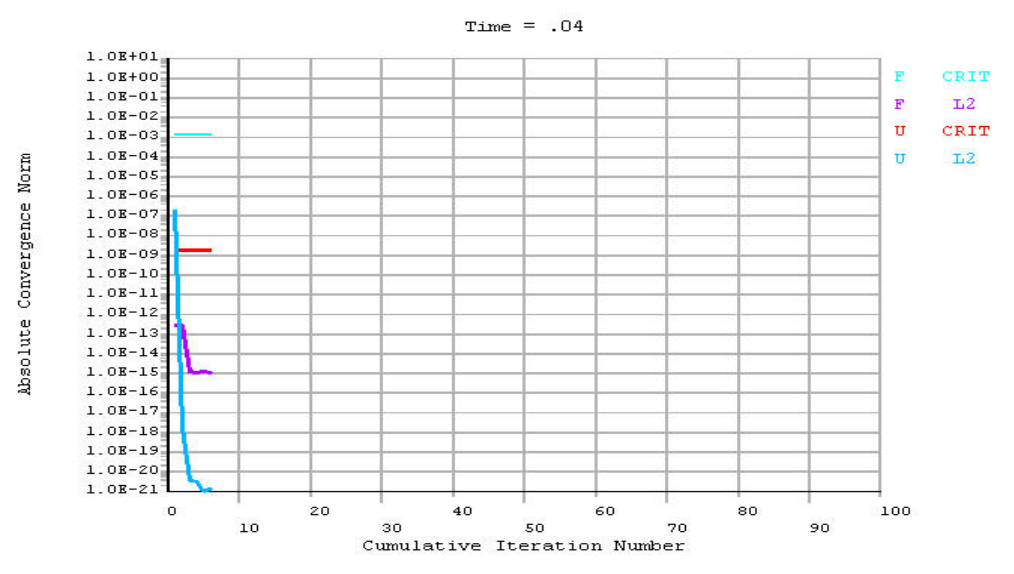

Figure 6 Solution Results of the First Loadstep

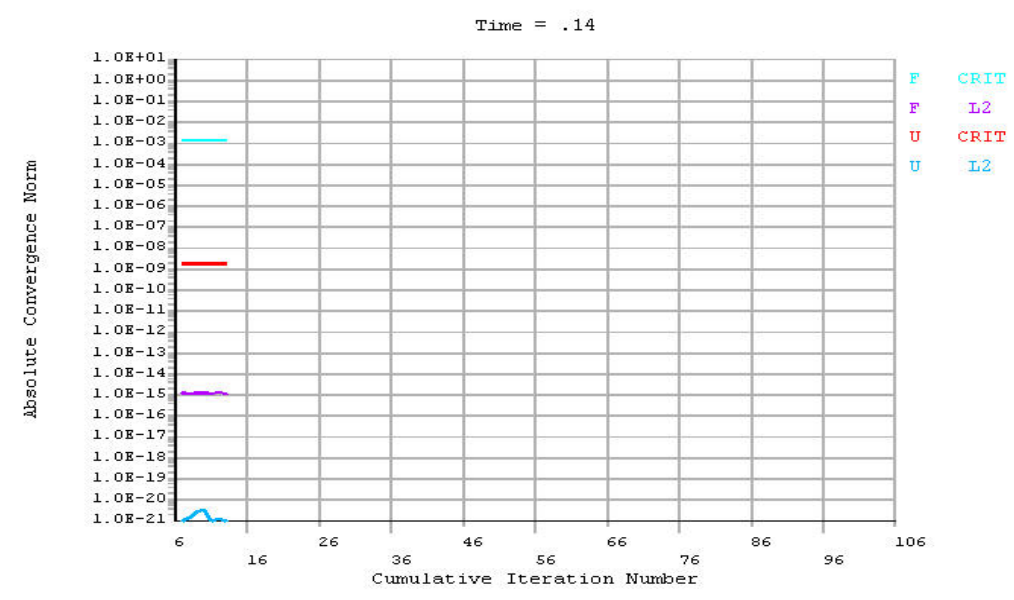

Figure 7, Solution Results of the Second Loadstep

\section{Setting Analysis Type and Applying Constraint Conditions}

The transient dynamic analysis is a means to determine the dynamic response of time-dependent load by structure. It can analysis time-dependent displacement, strain, stress and force under random combination of the static load, transient load and harmonic load [5]. The ladder stress is time-dependent, so this paper set the analysis type as transient and adopted FULL method [6].

The constraint of the first-section ladder is made by the upper hinges and hinges at the two ears. In the finite element model, it can be simplified: use 6DOF constraining the upper two arc surfaces for simulation.

\section{Solution of Finite Element Model}

The ladder is actually calculated to accommodate 2 people, the weight of each one is calculated as $75(735.5 \mathrm{~N})$, and considering the dynamic load coefficient of 1.35 , then: the ladder beam load $\mathrm{P} 1=735.52,1.35=1985.85 \mathrm{~N}$, the force on the model is reduced to $300 \mathrm{~N}$, density of $7.93 \mathrm{~g} / \mathrm{cm}^{3}$ is $0 \mathrm{Cr} 18 \mathrm{Ni}$, the quality of each ladder model is calculated about $2 \mathrm{~kg}$, th bottom of first-section ladder for each side is calculated as $2 \mathrm{~kg}$, which suffered from the pulling force of the lower ladders. Standing on the ladder beams has a process, thus this paper used the load steps for load calculation and analysis. 


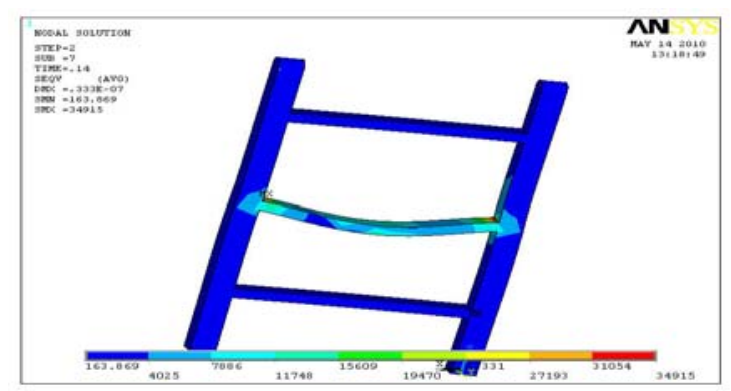

(a) aberrane phogram

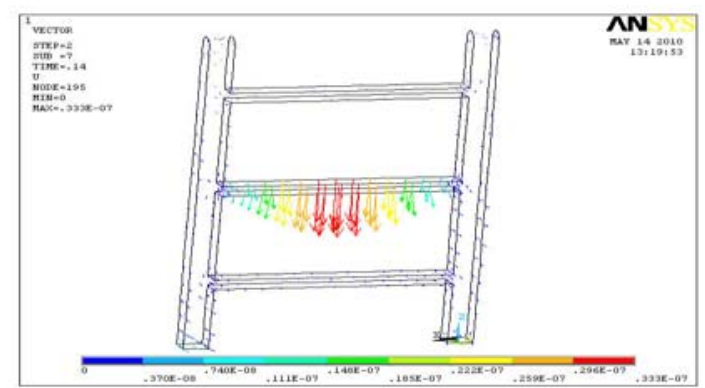

(b) stress distribution diagram

Figure 8, Stress Distribution Diagram of First-Section Ladder and Aberration Nephogram

\section{First Load Step Solution}

This paper opened the configuration window of analysis and solution option, set the Analysis Option in the Basic Tab as Small Displacement Transient, Time at end of loadstep as 0.04, closed the Automatic Time Stepping, set the substeps of 30 and printout as Every Substep for basic solution result, and saved the node solution result in each substep. This paper then set the load loading method as Stepped Loading in Transient Tab [4]. The solution is shown in Figure 6.

\section{Second Load Step Solution}

This paper opened the configuration window of analysis and solution option, set the Time at end of loadstep as 0.14 and substeps of 30 , printout the basic solution result, wherein the frequency is Every 5th Substeps. The solution is shown in Figure 7.

\section{Analysis of Finite Element Model}

This paper made finite element analysis for first-section ladder, wherein the stress unit is $\mathrm{Pa}$ and displacement unit is $\mathrm{m}$. The output stress is von Mises stress, which is an equivalent stress calculated by the fourth strength theory calculation. The vector sum (contour map of displacement) displacement shown is the total displacement of the node. When the load is distributed evenly, the finite element analysis results of ladder beam and aberration nephogram can be seen in Figure 8, wherein MX in Figure 8a and $\mathrm{b}$ respectively represent maximum displacement and maximum stress location.

According to the physical equation in the mechanics, ANSYS can be used to solve the stress component inside of the unit by the strain.

$$
\{\sigma\}=\left\{\begin{array}{l}
\sigma_{X} \\
\sigma_{Y} \\
\sigma_{Z}
\end{array}\right\}=\frac{E}{1-\mu^{2}}\left[\begin{array}{ccc}
1 & \mu & 0 \\
\mu & 1 & 0 \\
0 & 0 & \frac{1-\mu}{2}
\end{array}\right]\left\{\begin{array}{c}
\varepsilon_{X} \\
\varepsilon_{Y} \\
\varepsilon_{Z}
\end{array}\right\}
$$


Where in, $\sigma \mathrm{x}, \sigma \mathrm{y}, \sigma \mathrm{z}$ is normal stresses on the direction of $\mathrm{x}, \mathrm{y}, \mathrm{z}$, unit: $\mathrm{MPa}$;

E elasticity modulus of materials, unit: MPa;

$\mu$ Poisson's ratio of materials

$\varepsilon x, \varepsilon y, \varepsilon z$ strains on the direction of $x, y, z$

It can be seen from Figure 8a that, the largest displacement is situated in the middle part of the beam, whose value is $3.33 \times 10-5 \mathrm{~m}$; it can be seen from Figure $8 \mathrm{~b}$ that, the largest stress is situated between the both sides of beam and box iron welds, whose value is $3.5 \times 104 \mathrm{~Pa}$.

\section{Conclusions and Design Recommendations}

Through the finite element analysis for the rigidity of the first-section ladder, the following conclusions can be obtained:

(1) The ladder rigidity and strength satisfy the design requirements;

(2) The stresses inside of the ladder are not distributed evenly, the welding part on both sides of the beam has relatively large stress, reflecting as local concentration and local distribution. The amplitude change of the beam stress is big, other parts of the stress level are low, and the intensity of surplus is big, providing a theoretical basis for ladder design optimization and research.

Therefore, the design recommendations are given as below:

(1) To improve the stress at the stress peak value by local structural optimization, such as, laying a stiffener on both sides of the beam, optimizing the welding quality or proper increase of steel strength;

(2) To remain certain space for rigidity and strength on both sides of the steel frame, which can appropriately decrease the thickness of selected sectional material on both sides of the steel frame or adopt the steel materials with relatively small strength.

\section{References}

[1] Chuncheng WANG, Jingfeng YANG, Lijun WANG, et al, Finite Element Analysis and Optimal Design for Rolling Mill Rack, [J]. Machinery Design and Manufacture, 2009. 11, 11: 61-62.

[2] Anlin ZHANG, Hede WANG, Suspension Composite Materials Ladderway [J]. Coal Mine Design, 1995, 7: 17-21.

[3] Xiaoming MA, Zhenqiang YAO, Finite Element Analysis of the Longspan Portal Framed Structure [J]. Machinery Design and Research, 2008.12, 24(6): 72-74.

[4] Lirong WAN, Hanzheng DAI, Xin ZHANG, Finite Element Analysis of the Hydraulic Powered Support Based on Cosmos/Works [J]. Coal Mine Machinery, 2009.10,30(10):1-3.

[5] Fanping DENG, Self-Training Manual for ANSYS10.0 Finite Element Analysis [M]. Beijing: Posts and Telecom Press, 2007.1.

[6] Xiangxin LIU, Xianyi MENG, ANSYS Basics and Application Program [M], Beijing: Science Press, 2006.3.

[7] Jin DUAN, Dong NI, Guoye WANG, ANSYS 10.0 Structural Analysis: from Entry to Master, [M], Beijing: Weapon Industry Press, Beijing Kehai Electronic Press, 2006.10.

[8] Guidong HUANG, Guanglie SHEN, Zhilin WEI, et al, Improvement for Finite Element Analysis of Automobile Frame [J], Machinery Design, 2007.12,24(12):54-56.

[9] Min HU, Jianghong CUI, Bide CAO, Finite Element Analysis for the ZF7200/18/35 Hydraulic Support [J], Coal Mine Machinery, 2009.5,30(5):87-89.

[10] Hongwen LIU, Material Mechanics [M]. Beijing: Higher Education Press, 2004.1. 